\title{
Multi-aged micro-neighborhood patches challenge the forest cycle model in primeval European beech
}

\author{
Eric K Zenner (1), \\ Jerilynn E Peck ${ }^{(1)}$, \\ Volodymyr Trotsiuk ${ }^{(2-3-4)}$
}

\section{Introduction}

Widespread throughout the temperate Northern Hemisphere, dominant in much at least three continents, beech (Fagus) forests have been a persistent topic of applied research for over two centuries. For the last seven decades, the management of beech forests has drawn upon our understanding of structure and dynamics as framed by the pattern-process hypothesis of Europe, and economically important on

\begin{abstract}
As currently framed, the forest cycle model that underlies close-to-nature management in temperate beech forests throughout the globe specifies an orderly sequence of temporal development within even-aged patches comprising the forest mosaic. Although this model has been widely applied to European beech (Fagus sylvatica L.) forests, the underlying assumptions of disturbanceinduced even-agedness (i.e., within-patch age homogeneity) and competitioninduced size differentiation (i.e., within-patch size heterogeneity) have not been tested in natural beech forests due to prohibitions on tree coring in primeval forest reserves. In a rare and unprecedented test dataset of spatially explicit tree ages in an old-growth European beech forest, we employed triangulated irregular networks of Delaunay triangles to objectively identify natural tree neighborhoods to determine if neighboring (i.e., within-patch) trees were even- or, at most, two-aged. Age differences among neighboring trees (summarized in $25-\mathrm{yr}$ age classes) were rarely $<25 \mathrm{yrs}$ and mostly $>50 \mathrm{yrs}$, while the few "even-aged" patches were very small $\left(100 \mathrm{~m}^{2}\right)$ and relatively young $(<150$ yrs). In this first assessment of the assumptions underlying the forest cycle model in European beech, we observed neither the even-aged cohorts expected for disturbance-induced patches in different phases of development, nor the size differentiation among similarly aged trees that should arise from the neighborhood dynamics of competition, self-thinning, and growth. The lack of patches indicating demographic turnover is fundamentally inconsistent with the forest cycle model as it is currently framed. We call for further exploration of spatially-explicit tree age datasets to determine the generality of these observations.
\end{abstract}

Keywords: Age Reconstruction, Carpathians, Dendrochronology, Development Stage, Forest Cycle, Stand Development, Structure, Triangulated Irregular Network (TIN) embedded in the conceptual patch mosaic model (Watt 1947). Central to this model is the recognition of the patch as the fundamental spatial unit embodying forest development, such that forest dynamics are reflected in a complex space-time-structure mosaic formed by the assemblage of patches (Bormann \& Likens 1979, Remmert 1991, Wu \& Loucks 1995). Patches are more-or-less discrete spatial and temporal entities differentiated by floristic composi-
(1) Department of Ecosystem Science and Management, The Pennsylvania State University, University Park, PA, 16802 (USA); (2) Faculty of Forestry and Wood Sciences, Czech University of Life Sciences Prague, Kamycka 129, Prague (Czech Republic); (3) Swiss Federal Institute for Forest, Snow and Landscape Research WSL, Birmensdorf (Switzerland); (4) Institute of Agricultural Sciences, ETH Zurich, Zurich (Switzerland)

@ Eric K Zenner (eric.zenner@psu.edu)

Received: Dec 03, 2019 - Accepted: Apr 10, 2020

Citation: Zenner EK, Peck JE, Trotsiuk V (2020). Multi-aged micro-neighborhood patches challenge the forest cycle model in primeval European beech. iForest 13: 209-214. - doi: 10.3832/ifor3309-013 [online 2020-06-06]

Communicated by: Jesus Julio Camarero tion, age, size distribution, or structure (Leibundgut 1959, Korpel 1995, Král et al. 2014). Rather than merely reflecting the life history (e.g., birth, growth, and death) of individual trees, patches are thought to capture the demographic turnover of tree generations (i.e., the forest life cycle Watt 1947). In temperate European beech (Fagus sylvatica L.) old-growth forests, patches arise through disturbances that typically range between several hundred to a few/several thousand square meters (Drössler \& Von Lüpke 2005, Král et al. 2010, Král et al. 2014), exceeding the scale of individual canopy gaps following the death of a single or a small group of trees (Podlaski 2008) to encompass greater extents of synchronized, spatially and temporally confined canopy break-up (Paluch 2007).

The forest cycle model stipulates that these newly initiated patches pass as a cohort through an orderly temporal sequence of development phases in which the initial upgrade phases associated with birth, growth, and biomass accumulation (i.e., renewal / regeneration / early growth phases) peak in the mature phase following the death of dominant trees, and end in 
a downgrade series of phases (i.e., ageing / breakdown / decay phases) associated with dead, dying, and rotting stems, declining biomass, and ultimately the initiation of a new tree generation (Watt 1947, Bormann \& Likens 1979, Remmert 1991). Patch cohorts are thus conceptualized as roughly even-aged, cycling in age and structure over time but more-or-less homogeneous in age structure within the patch at any given point in time (Leibundgut 1959, Remmert 1991). At the same time, natural beech forests are known to be structurally diverse and multi-sized (Westphal et al. 2006). This within-patch size heterogeneity is generally attributed to neighborhood dynamics (i.e., inter-tree competition, selfthinning, and growth and size differentiation) that structurally diversifies the roughly even-aged patches over time (Pacala et al. 1996, Gratzer et al. 2004) and drives progression through the series of development phases in the forest cycle.

However, despite the wide application of the patch mosaic model in temperate oldgrowth forests (Král et al. 2010) and a long history of patch dynamics modeling (Wu \& Loucks 1995), the central assumption of the forest cycle model (i.e., the existence of even-aged patches that become structurally diversified over time) has rarely been challenged (Král et al. 2018) and never, to our knowledge, empirically verified. Historically, the dynamics underlying the forest life cycle model have been inferred from descriptions of forest structure (e.g., diameter distributions, canopy stratification, mortality rates, amount of deadwood, regeneration - Leibundgut 1959, Král et al. 2010, 2014, 2018, Zenner et al. 2015). More recently, dendrochronological methods have become available to facilitate verification, but prohibitions of tree coring in the few remaining remnants of natural beech forest (Trotsiuk et al. 2012) have permitted only sparse and spatially dispersed sampling to sketch overall stand age structure, identify establishment and release periods, and characterize past dis- turbances (Splechtna et al. 2005, Zielonka et al. 2010). Moving beyond descriptive classifications to quantitatively assess the assumptions of the forest cycle model requires the innovative approach of reconstructing ages within actual tree neighborhoods to determine if trees within a patch are indeed even- or, at most, two-aged.

The current reconstruction was made possible by unprecedented permission to destructively sample in the Uholka-Shyrokyi Luh reserve within the primeval beech forest of the Carpathian Biosphere Reserve. We take advantage of a rare complete inventory of individual tree ages in portions of this old-growth forest (Trotsiuk et al. 2012) for a novel, spatially explicit analysis seeking demographic evidence of the implicit assumptions of the forest cycle model. In this first quantitative validation of the model, we test whether or not objectively defined neighborhoods of adjacent trees demonstrate within-patch age homogeneity (i.e., are even-aged) and if comparably aged trees demonstrate size heterogeneity. Although limited in scope, we hope this work will spur additional exploration into the assumptions and framework of the model that forms the theoretical basis for applied forest restoration and sustainable management in temperate forest ecosystems.

\section{Materials and methods}

The data collection methods for the raw data were reported in detail in Trotsiuk et al. (2012). Sampling took place in a primeval European beech (Fagus sylvatica L.) forest at $660-730 \mathrm{~m}$ a.s.l. on south-east facing slopes of $30-45 \%$ within the core $\left(48^{\circ} 25^{\prime} \mathrm{N}\right.$, $\left.23^{\circ} 61^{\prime} \mathrm{E}\right)$ of the Uholka-Shyrokyi Luh reserve in the temperate Ukrainian Carpathians, which averages $7.7^{\circ} \mathrm{C}$ with annual precipitation of $1134 \mathrm{~mm}$ (Hamor \& Brändli 2013). Four 0.1 ha circular plots (Tab. 1) $\sim 200 \mathrm{~m}$ apart were selected in 2010 to be collectively representative of the range of size structures found in a nearby permanent monitoring area in which tree coring

Tab. 1 - Mean ( \pm standard deviation) values for each plot. Mean age ${ }^{A}$ was calculated across all trees, while Max age ${ }^{R}$ was calculated only across trees with reliable ages. Max age ${ }^{\dagger}$ was calculated across all trees, but capped at 500 yrs for analysis. Note that averages for the Min and Max age ${ }^{\dagger}$ are based on individual trees rather than the plot level.

\begin{tabular}{|c|c|c|c|c|c|}
\hline \multirow{2}{*}{ Parameter } & \multicolumn{4}{|l|}{ Plots } & \multirow{2}{*}{ Average } \\
\hline & 1 & 2 & 3 & 4 & \\
\hline Mean age ${ }^{A}[y r]$ & $206 \pm 141$ & $132 \pm 86$ & $245 \pm 121$ & $244 \pm 101$ & $207 \pm 112$ \\
\hline Min age $[y r]$ & 57 & 43 & 84 & 91 & 112 \\
\hline Max age ${ }^{\dagger}[y r]$ & 647 & 506 & 545 & 464 & 541 \\
\hline Max age ${ }^{R}[y r]$ & 166 & 295 & 460 & 417 & 335 \\
\hline Basal area $\left[\mathrm{m}^{2} \mathrm{ha}^{-1}\right]$ & 63.5 & 30.9 & 62.7 & 40.8 & 49.5 \\
\hline Tree density [stems ha ${ }^{-1}$ ] & 370 & 590 & 410 & 270 & 410 \\
\hline Mean Diameter [cm] & 31 & 17.3 & 31.6 & 35.3 & 28.8 \\
\hline Quadratic Mean Diameter [cm] & 46.7 & 25.8 & 44.1 & 43.9 & 39.2 \\
\hline Max Diameter [cm] & 108 & 98 & 90 & 95 & 98 \\
\hline
\end{tabular}

was not permitted, which is now known to be dominated by structural conditions indicative of downgrade phases (Peck et al. 2015, Zenner et al. 2015). Within each plot, the diameter at breast height $(1.3 \mathrm{~m})$ and spatial location were recorded for all live trees with diameters $\geq 6 \mathrm{~cm}$ (all European beech). All sampled trees $(\mathrm{N}=164)$ were cored parallel to the slope at either $100 \mathrm{~cm}$ above the ground (143 trees) or, when not possible, at $80 \mathrm{~cm}$ ( 21 trees). One to two saplings per plot were randomly selected and cross sectioned in $20 \mathrm{~cm}$ intervals upwards from the root collar to estimate the years required to reach coring height. Although Acer was common in the regeneration layer of the nearby permanent monitoring area, trees of breast height were nearly pure (95\%) European beech (Commarmot et al. 2005).

Measurement of tree ring widths and detailed cross-dating methods are described in Trotsiuk et al. (2012). Annual ring widths were measured using a stereomicroscope and a LintabTM sliding-stage measuring station, in tandem with the TSAP-WinTM software (Rinntech, Heidelberg, Germany). The best synchronized ring-width series was used to construct a master-chronology, in which negative pointer years made precise dating of all 164 cores over the past 200 years possible. Cross-dated ring series were used to directly determine the ages of $32 \%$ of trees, while $46 \%$ were estimated after fitting concentric circles to the curvature of the inner rings and predicting the number of rings in early life given a constant growth rate (Duncan 1989). For the $22 \%$ of trees with a rotten core, the length of the radius was taken as the difference between the geometrical radius and total core length (Rozas 2003) and then the missing age was computed from an age-radius equation based on the cumulative growth of complete tree cores, capped at 500 years (4 trees). Finally, based on the sapling data, 11 years were added to trees cored at $100 \mathrm{~cm}$ and 9 years to those cored at $80 \mathrm{~cm}$. Trees for which the core reached the pith or no more than 20 years of missing age had to be added $(n=116)$ are considered to have "reliable" age estimates.

In the current study, trees were assigned to 25-year age classes (starting at 50) and the relative abundance of trees in each age class was computed, by plot and averaged across plots. To asses within-patch evenagedness (i.e., if adjacent trees belonged to the same cohort, reflecting age homogeneity), we first used spatial tessellation to objectively identify neighboring trees by creating a triangulated irregular network of maximally equilateral Delaunay triangles (i.e., Delaunay TINs), which optimally connects horizontally adjacent trees to one another in three-tree micro-neighborhood patches (e.g., Fig. 1i in Zenner \& Peck 2018). Age differences at the micro-neighborhood level were then computed as the maximum difference in absolute ages among the three constituent trees, which were then 
assigned to 25-yr difference classes for which the relative abundance was computed by plot and averaged across plots. To quantify within-patch even-agedness, three categories of age differences were recognized: (i) even-aged, when only one age difference class was observed (i.e., all three trees were within 25 yrs in age); (ii) two-aged, when two age classes were observed; or (iii) multi-aged, if all three trees belonged to different age difference classes. The cumulative area within each plot of all micro-neighborhoods belonging to each age-difference class was also summed. Size differences at the micro-neighborhood level were computed as the maximum difference in diameter among the three constituent trees of each microneighborhood patch, which were then assigned to $10-\mathrm{cm}$ difference classes. To assess within-patch uneven-sizedness (i.e., if adjacent trees differed in size, reflecting size heterogeneity), three categories of size differences were recognized: (i) evensized, if only one size difference class was observed (i.e., all three trees were within $10 \mathrm{~cm}$ in diameter); (ii) two-sized, if two size classes were observed; or (iii) multisized, if all three trees belonged to different size difference classes. Computations were performed in Matlab ${ }^{T M}$ v. 8.2.0 (Math- works Inc., Natick, MA, USA). Average differences in tree diameter within even-aged micro-neighborhoods were compared to those across all micro-neighborhoods using a paired t-test $(\mathrm{N}=4)$ in $\mathrm{SAS}^{\oplus} \mathrm{v} \cdot 9.3$ (SAS Institute, Cary, NC, USA).

\section{Results}

Reliable ages of these $\geq 6 \mathrm{~cm}$ trees ranged from 43 to 470 years (Tab. 1). The 25-year age class distributions (Fig. 1) varied among plots from multi-modal with missing age classes to more evenly distributed and relatively continuous. At least some trees became established in the majority of 25-year periods in each plot over the entire ca. 450-year period, and when averaged across all plots tree establishment was detected in every 25 -year period (Fig. 1e). In plot 1 , only $24 \%$ of micro-neighborhood patches had within-patch maximum age differences of less than 50 years and almost as many (22\%) differed by over 400 years; the majority of micro-neighborhoods had age differences among trees between $175-400$ years (Fig. 1f). In plot 2, 52\% of all micro-neighborhoods differed in age by less than 50 years and only $7 \%$ by over 225 years (Fig. 1g). While plot 3 had a peak (35\%) in age differences less than 50 years (Fig. 1h), in plot 4 the micro-neighborhoods exhibited age differences up to 350 years in very similar proportions (all classes < $14 \%$ ) and no micro-neighborhood differed in age by more than 350 years (Fig. 1i).

Few micro-neighborhood patches were even-aged: when averaged across plots, only $14 \% \pm 13 \%$ (standard deviation, std) of micro-neighborhoods differed in age by less than 25 years and only $28 \% \pm 19 \%$ by less than 50 or even 100 years. In contrast, a cumulatively equal number had age differences of 150-275 years (Fig. 1j). The proportion of micro-neighborhoods was surprisingly comparable among age differences ranging from 50 to over 400 years (each class averaging $<10 \%$ ). Two-aged microneighborhoods comprised 31\% $\pm 9 \%$, 34\% \pm $9 \%$, and $51 \% \pm 13 \%$ of neighborhoods when age difference cutoffs of $<25,<50$, and $<100$ years were used, respectively. Using those same cutoffs, multi-aged microneighborhoods made up 55\% $\pm 20 \%, 38 \% \pm$ $17 \%$, and $21 \% \pm 9 \%$ of all neighborhoods, respectively.

Using a $10 \mathrm{~cm}$ size difference cutoff, roughly one quarter $(24 \% \pm 16 \%$, std) of all micro-neighborhood patches were evensized, $34 \% \pm 6 \%$ two-sized, and $42 \% \pm 19 \%$ multi-sized. On average within micro-neighborhoods, mean tree diameter increased with increasing tree age, although diame-
Fig. 1 - Age homogeneity. Distribution of individual tree ages by 25-yr age classes in each plot (A$D$, dark grey) and across all plots (E, blue), and of micro-neighborhoods (i.e., patches) by $25-y r$ age difference classes in each plot (F-I, light grey) and across all plots (J, red).

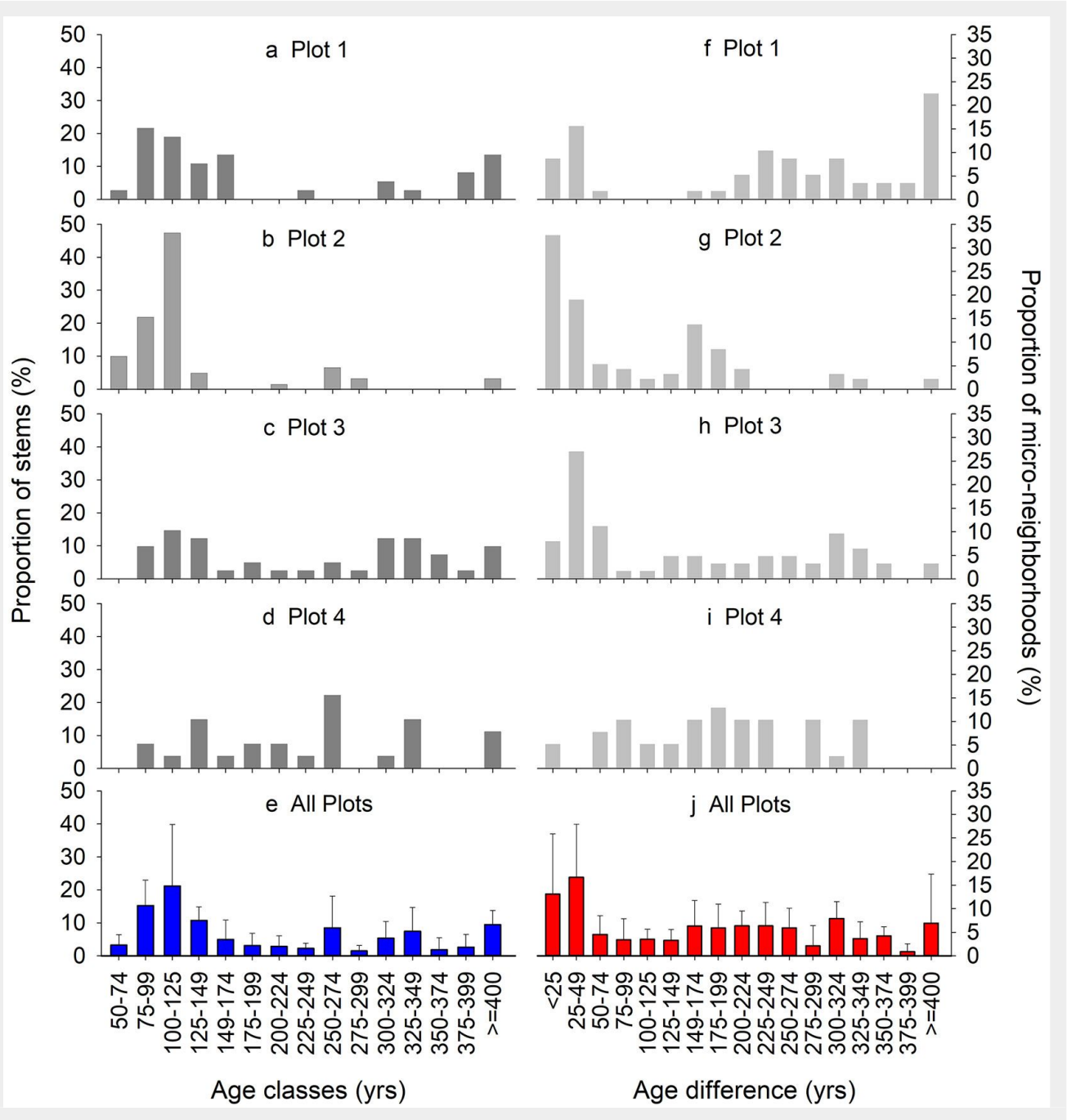




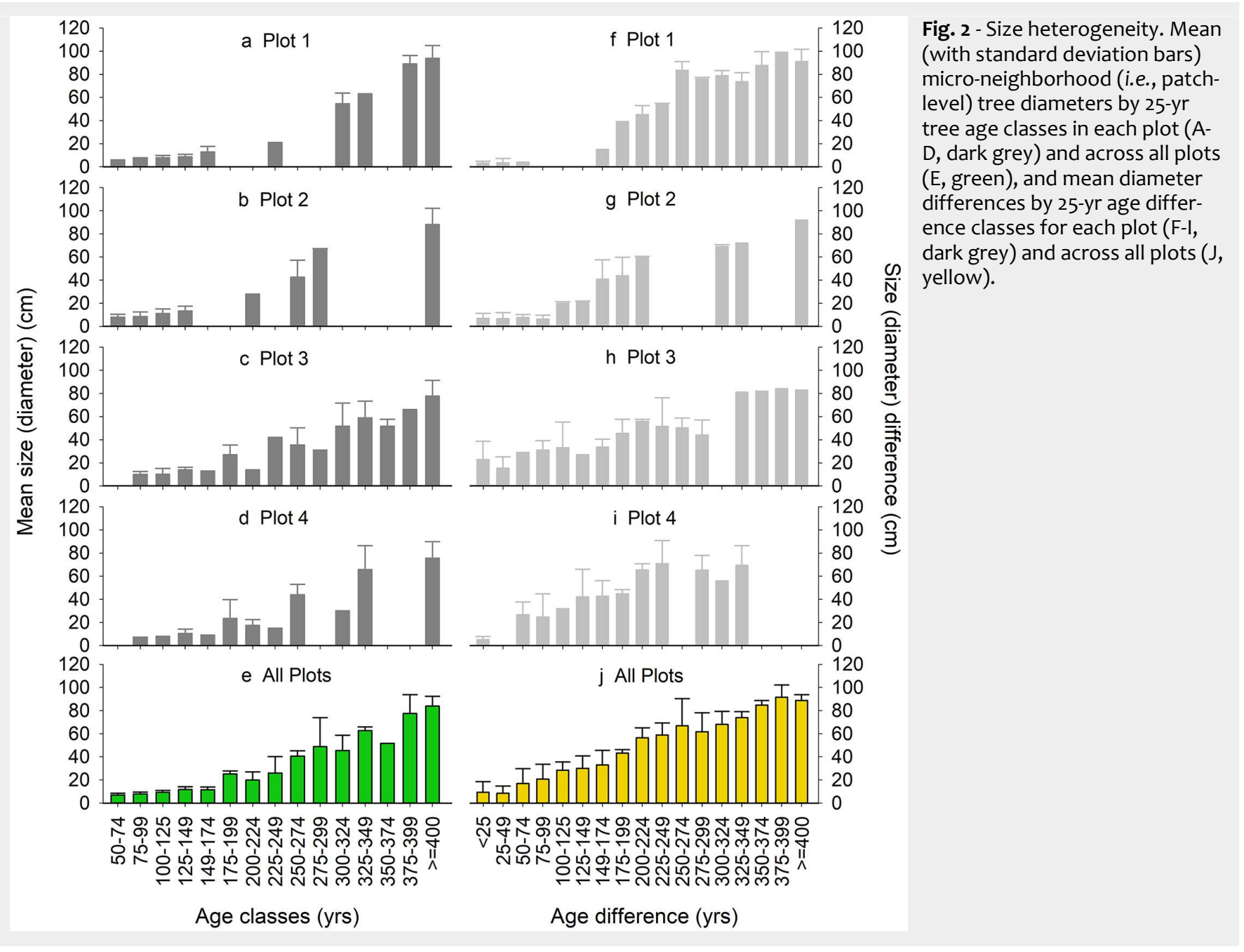

ters remained fairly consistently low $(<20$ $\mathrm{cm}$ ) up to $175 \mathrm{yrs}$ in age (Fig. 2e). Despite considerable differences in age among comparably sized trees (see Fig. S1 and Fig. S2 in Supplementary material), even-aged micro-neighborhoods (up to 50-yr differences) were largely composed of similarly sized trees (Fig. 2j). On average, diameter differences among adjacent trees were smaller in neighborhoods composed of even-aged trees, based on both a $25 \mathrm{yr}$ age difference (by $32 \pm 9 \mathrm{~cm}$, std) and even a $100 \mathrm{yr}$ age difference (by $29 \pm 8 \mathrm{~cm}$ - both $\mathrm{p}=0.04$ ), ranging from $9.4 \pm 9.1 \mathrm{~cm}$ for even-aged micro-neighborhoods that spanned a $25 \mathrm{yr}$ age difference to $12.8 \pm 9.0 \mathrm{~cm}$ for those that spanned $100 \mathrm{yr}$ age differences.

The high proportion of micro-neighborhood patches with large age differences reflects the close proximity of trees belonging to differing age classes. All plots demonstrated substantial intermingling of differently aged trees, such that microneighborhoods contained trees belonging to most age class combinations. Not only were none of these small plots composed primarily of even-aged trees (and only one with barely $>50 \%$ of even-aged + twoaged), but within plots there were few contiguous patches of similarly-aged trees (see Fig. S3 in Supplementary material).
The sum of micro-neighborhoods in which tree ages differed by less than 25 years averaged only $100 \pm 95 \mathrm{~m}^{2}$ (range: $28-240 \mathrm{~m}^{2}$ ). Even the cumulative spatial extents of micro-neighborhoods in which tree ages differed by less than 100 years averaged only $287 \mathrm{~m}^{2}$ (38\% of the sum of micro-neighborhood convex hull areas) and ranged from $152-499 \mathrm{~m}^{2}(27-62 \%)$

\section{Discussion}

Although this study represents a necessarily retrospective case-study of limited statistical inference, it provides rare and unprecedented empirical data addressing the demographic predictions of the forest cycle model. In this first attempt to validate the model, we failed to observe either the even-aged patches reflective of disturbance-driven within-patch age homogeneity (Leibundgut 1959, Remmert 1991) or the uneven-sizedness of comparably aged trees reflective of neighborhood dynamicsdriven size heterogeneity (Pacala et al. 1996, Gratzer et al. 2004). First, neighboring trees were not mostly similarly aged, even when adopting the relaxed definition of even-agedness as a single age class with a range of tree ages $<20 \%$ of the "rotation" age (100 years assuming a 500-year beech life span/rotation - Helms 1998). Second, similarly aged trees (even when they were adjacent) were similar in size up to 175 years of age, such that the range of tree sizes observed cannot be predominantly attributed to competitive stratification in even-aged patches.

Rather, we observed an irregular mosaic of structurally variable patches composed of uneven-aged trees (spanning >376 yrs within a mere $0.1 \mathrm{ha}$ ) that was a function of intensive intermixing of young and old trees. Every plot had trees belonging to 914 different 25-year age classes and tree establishment spanning the majority of the $400+$ year history, indicating essentially continuous recruitment rather than temporally discrete cohorts. Trees of the same size reflected regeneration events up to a century apart (one fifth of the lifespan of European beech - Di Filippo et al. 2015), a majority of micro-neighborhoods had age differences $>150 \mathrm{yrs}$, and more than a third were multi-aged. The few even-aged neighborhoods that were observed encompassed cumulative extents averaging only $100 \mathrm{~m}^{2}$ at age differences $<25 \mathrm{yrs}$ (i.e., less than the ca. $156 \mathrm{~m}^{2}$ spatial extent of a single canopy beech tree - Meyer 1999), only $287 \mathrm{~m}^{2}$ at $<100 \mathrm{yr}$ differences, and were not spatially contiguous.

Given the structural representativeness of these plots to the intensively-studied nearby 10 ha monitoring plot (Commarmot 
et al. 2005) and of that plot to the 10,000 ha reserve in which it is situated (Peck et al. 2015), these observations may not be atypical. Although further dendrological work in a wider array of field sites will be required to definitively assess the validity of the forest cycle model in natural beech forest, the patterns of the current study are consistent with the age span (hundreds of years - Piovesan et al. 2005) and complex age structure (Di Filippo et al. 2017) of other beech forests, the silvics of European beech (which has the capacity for continuous initiation and establishment - Wagner et al. 2010), and the small scale of the predominant disturbance regime (tens to hundreds of $\mathrm{m}^{2}$ - Drössler \& Von Lüpke 2005, Zeibig et al. 2005). In fact, the key to the observed pattern of intimate intermingling of tree generations may be the successful release (either continuously or in disturbance pulses - Nagel et al. 2014) of understory regeneration at extremely fine scales. The main exogenous disturbance agent in these forests is wind (Westphal et al. 2006) and stem breakage the prevailing mode of mortality (Zeibig et al. 2005). If beech regeneration is able to respond to release in mini-gaps on the scale of individual branch breakage, the result of such frequent and spatially and temporally asynchronous small-scale disturbance would be to create and maintain the multilayered stand structures (Commarmot et al. 2005, Westphal et al. 2006, Kucbel et al. 2010) associated with multi-/all-agedness (Paluch 2007). Subsequently, the intermingling of tree generations could reflect the successful release of continuously establishing understory regeneration (Piovesan et al. 2005) at the extremely fine scales of the prevailing mode of mortality, as suggested by a stop-and-go growth release pattern (Trotsiuk et al. 2012, Nagel et al. 2014). Our results thus support the structure-based findings by Paluch (2007) that patches are rarely homogeneous at scales exceeding the crown size of one or a few canopy trees, which would explain the inadequacy of development phases to explain the cross-scale multi-/all-agedness of old-growth European beech forests (Paluch 2007).

Multi-/all-agedness implies that demographic turnover is continuous in time and space, undermining the delineation of demographic turnover from "one tree generation to another" (Leibundgut 1959) that is fundamental to the forest cycle model. Although it is possible that some of the plots in the current study could be classified to the Plenter (sensu Korpel 1995) phase (as was the case for the nearby monitoring plot - Zenner et al. 2015) on the basis of structural conditions reflecting an accumulation of biomass in a young cohort beneath residuals from the previous cohort (as per Korpel 1995), it could not be argued that stands spanning eight age classes are two-aged, as Korpel further implies, or in an early temporal "up-growing" phase. This may explain why the "Plenter" steady- state phase has been persistently placed outside of the development cycle (Leibundgut 1959, Král et al. 2010), is purportedly not very common in old-growth forests (Korpel 1995), has never received a satisfactory ecological explanation under the patch mosaic model (Král et al. 2010), and is underestimated in importance (Král et al. 2014), even though the age and size structure of this phase most closely portrays the fine-scale heterogeneity consistently documented in temperate oldgrowth forests characterized by small-scale gap dynamics (Paluch 2007, Paluch et al. 2015). Thus any model of the dynamics of pattern and process in beech forests must be considered within the context of a disturbance regime that maintains the multiage as well as multi-size structures observed here and in other old-growth beech forests (Di Filippo et al. 2017).

Our results are not, however, inconsistent with Watt's (1947) central idea of an upgrade and downgrade series of structurally distinct patches (Leibundgut 1959), likely reflecting processes linked to the persistence of large/old overstory trees (Paluch 2007), repeated release of midstory trees (Trotsiuk et al. 2012), and continuous presence of understory trees (Commarmot et al. 2005). Multi-agedness results in different allocations of growing stock to various age (and size) classes and canopy layers (Lorimer \& Halpin 2014), and it is the variability in age hierarchy across space that gives the impression of patchiness. In this context, discrete phases based upon structural criteria ("structure" phases) may still be useful for describing the hierarchical, nested, cyclic space-time dynamics of spatially shifting patches in old-growth forests (Watt 1947, Wu \& Loucks 1995).

\section{Conclusions}

Although limited in scope, this first use of spatially explicit age reconstructions to validate the forest cycle model failed to detect either even-aged patches or unevensizedness in comparably aged trees. Instead, we exclusively observed structurally variable, uneven-aged patches of intensively intermixed young and old trees. If these observations were to prove typical, and multi-aged structural phases were found in other primeval European beech forests to frequently predominate over even-aged developmental stages, the conceptual model of the forest cycle may prove unrealistic and thus impede efforts at conservation, restoration, and sustainable forest management (Kuuluvainen 2016). At the same time, the prevalence of multilayered stand structures with multi-/ all-agedness does not preclude the use of structure phases to describe the patch mosaic.

\section{Acknowledgements}

We are grateful to the Carpathian Biosphere Reserve for permitting tree coring in the Uholka virgin beech forest (Ukraine).
EZ conceived the approach; all authors developed the methodology; VT acquired data; EZ performed statistical analyses; JP and EZ wrote the first draft of the manuscript and all authors contributed to the final version. This work was supported by the USDA National Institute of Food and Agriculture Hatch Appropriations under Project \#PEN04639 and Accession \#1015105.

\section{References}

Bormann FH, Likens GE (1979). Catastrophic disturbance and the steady state in northern hardwood forests: a new look at the role of disturbance in the development of forest ecosys tems suggests important implications for landuse policies. American Scientist 67: 660-669. [online] URL: http://www.jstor.org/stable/2784 9531

Commarmot B, Bachofen H, Bundziak $Y$, Bürgi A, Ramp B, Shparyk Y, Sukhariuk D, Viter R, Zingg A (2005). Structures of virgin and managed beech forests in Uholka (Ukraine) and Sihlwald (Switzerland): a comparative study. Forest Snow and Landscape Research 79: 45-56. [online] URL: http://www.researchgate.net/publi cation/268261842

Di Filippo A, Biondi F, Piovesan G, Ziaco E (2017). Tree ring-based metrics for assessing oldgrowth forest naturalness. Journal of Applied Ecology 54: 737-749. - doi: 10.1111/1365-2664.12 793

Di Filippo A, Pederson N, Baliva M, Brunetti $M$, Dinella A, Kitamura K, Knapp HD, Schirone B, Piovesan $G$ (2015). The longevity of broadleaf deciduous trees in Northern Hemisphere temperate forests: insights from tree-ring series. Frontiers in Ecology and Evolution 3: 347. - doi: 10.3389/fevo.2015.00046

Drössler L, Von Lüpke B (2005). Canopy gaps in two virgin beech forest reserves in Slovakia. Journal of Forest Science 51: 446-57. - doi: 10.17221/4578-JFS

Duncan RP (1989). An evaluation of errors in tree age estimates based on increment cores in Kahikatea (Dacrycarpus dacrydioides). New Zealand Natural Sciences 16: 31-37. [online] URL: http://researchprofiles.canberra.edu.au/en/publ ications/an-evaluation-of-errors-in-tree-age-esti mates-based-on-increment-

Gratzer G, Canham C, Dieckmann U, Fischer A, Iwasa Y, Law R, Lexer MJ, Sandmann H, Spies TA, Splechtna BE, Szwagrzyk J (2004). Spatiotemporal development of forests-current trends in field methods and models. Oikos 107: 3-15. - doi: 10.1111/j.0030-1299.2004.13063.x Hamor F, Brändli U-B (2013). The Uholka-Shrokyi Luh protected massif - an overview. In: "Inventory of the Largest Primeval Beech Forest in Europe - A Swiss-Ukrainian Scientific Adventure" (Commarmot B, Brändli U-B, Hamor F, Lavnyy V eds). Swiss Federal Research Institute WSL, Birmensdorf, Ukrainian National Forestry University, L'viv, Carpathian Biosphere Reserve, Rakhiv, Ukraine, pp. 13-17.

Helms JA (1998). The dictionary of forestry. Society of American Foresters, Bethesda, USA, pp. 210.

Korpel S (1995). Die Urwälder der Westkarpaten [The primeval forests of the Western Carpathi- 
ans]. Gustav Fischer Verlag, Stuttgart, Germany, pp. 310. [in German]

Král K, Vrška T, Hort L, Adam D, Samonil P (2010). Developmental phases in a temperate natural spruce-fir-beech forest: determination by a supervised classification method. European Journal of Forest Research 129: 339-351. doi: 10.1007/s10342-009-0340-0

Král K, McMahon SM, Janík D, Adam D, Vrška T (2014). Patch mosaic of developmental stages in central European natural forests along vegetation gradient. Forest Ecology and Management 330: 17-28. - doi: 10.1016/j.foreco.2014.06. 034

Král K, Danek P, Janík D, Kruček $M$, Vrška $T$ (2018). How cyclical and predictable are Central European temperate forest dynamics in terms of development phases? Journal of Vegetation Science 29: 84-97. - doi: 10.1111/jvs.12590

Kucbel S, Jaloviar P, Saniga M, Vencurik J, Klimaš $\checkmark$ (2010). Canopy gaps in an old-growth firbeech forest remnant of Western Carpathians. European Journal of Forest Research 129: 249259. - doi: 10.1007/s10342-009-0322-2

Kuuluvainen T (2016). Conceptual models of forest dynamics in environmental education and management: keep it as simple as possible, but no simpler. Forest Ecosystems 3: 1-9. - doi: 10.1186/s40663-016-0075-6

Leibundgut H (1959). Uber Zweck und Methoden der Struktur-und Zuwachsanalyse von Urwäldern [On the purpose and methods of structure and growth analysis in primeval forests]. Schweizerische Zeitschrift für Forstwesen 110: 111-124. [in German]

Lorimer CG, Halpin CR (2014). Classification and dynamics of developmental stages in late-successional temperate forests. Forest Ecology and Management 334: 344-357. - doi: 10.1016/j. forec0.2014.09.003

Meyer P (1999). Bestimmung der Waldentwicklungsphasen und der Texturdiversität in Naturwäldern [Determination of forest development phases and the textural diversity of natural forests]. Allgemeine Forst- und Jagdzeitung 170: 203-211. [in German]

Nagel TA, Svoboda M, Kobal M (2014). Disturbance, life history traits, and dynamics in an old-growth forest landscape of southeastern Europe. Ecological Applications 24: 663-679. doi: 10.1890/13-0632.1

Pacala SW, Canham CD, Saponara J, Silander JA, Kobe RK, Ribbens E (1996). Forest models de- fined by field measurements: estimation, error analysis and dynamics. Ecological Monographs 66: 1-43. - doi: 10.2307/2963479

Paluch JG (2007). The spatial pattern of a natural European beech (Fagus sylvatica L.) - silver fir (Abies alba Mill.) forest: a patch-mosaic perspective. Forest Ecology and Management 253: 161-170. - doi: 10.1016/j.foreco.2007.07.013

Paluch JG, Kolodziej Z, Pach M, Jastrzebski R (2015). Spatial variability of close-to-primeval Fagus-Abies-Picea forests in the Western Carpathians (Central Europe): a step towards a generalised pattern. European Journal of Forest Research 134: 235-246. - doi: 10.1007/s10342-0140846-y

Peck JE, Commarmot B, Hobi ML, Zenner EK (2015). Should reference conditions be drawn from a single 10-ha plot? Assessing representativeness in a 10,000-ha old-growth European beech forest. Restoration Ecology 23: 927-935. doi: $10.1111 /$ rec.12258

Piovesan G, Di Filippo A, Alessandrini A, Biondi F, Schirone B (2005). Structure, dynamics and dendroecology of an old-growth Fagus forest in the Apennines. Journal of Vegetation Science 16: 13-28. - doi: 10.1111/j.1654-1103.2005.tbo233 4.x

Podlaski R (2008). Dynamics in Central European near-natural Abies-Fagus forests: does the mosaic-cycle approach provide an appropriate model? Journal of Vegetation Science 19: 173182. - doi: 10.3170/2008-8-18350

Remmert H (1991). The mosaic-cycle concept of ecosystems an overview. In: "The mosaic-cycle concept of ecosystems" (Remmert H ed). Springer, Berlin, Heidelberg, Germany, pp. 1-21. Rozas V (2003). Regeneration patterns, dendroecology, and forest-use history in an oldgrowth beech-oak lowland forest in Northern Spain. Forest Ecology and Management 182: 175-194. - doi: 10.1016/S0378-1127(03)00070-7

Splechtna BE, Gratzer G, Black BA (2005). Disturbance history of a European old-growth mixedspecies forest - A spatial dendro-ecological analysis. Journal of Vegetation Science 16: 511-522. doi: 10.1111/j.1654-1103.2005.tbo2391.x

Trotsiuk V, Hobi ML, Commarmot B (2012). Age structure and disturbance dynamics of the relic virgin beech forest Uholka (Ukrainian Carpathians). Forest Ecology and Management 265: 181190. - doi: 10.1016/j.foreco.2011.10.042

Wagner S, Collet C, Madsen P, Nakashizuka T, Nyland RD, Sagheb-Talebi K (2010). Beech re- generation research: from ecological to silvicultural aspects. Forest Ecology and Management 259: 2172-2182. - doi: 10.1016/j.foreco.2010.02.0 29

Watt AS (1947). Pattern and process in the plant community. Journal of Ecology 35: 1-22. - doi: $10.2307 / 2256497$

Westphal C, Tremer N, Von Oheimb G, Hansen J, Von Gadow K, Härdtle W (2006). Is the reverse J-shaped diameter distribution universally applicable in European virgin beech forests? Forest Ecology and Management 223: 75-83. - doi: 10.1016/j.foreco.2005.10.057

Wu J, Loucks OL (1995). From balance of nature to hierarchical patch dynamics: a paradigm shift in ecology. The Quarterly Review of Biology 70: 439-466. - doi: 10.1086/419172

Zeibig A, Diaci J, Wagner S (2005). Gap disturbance patterns of a Fagus sylvatica virgin forest remnant in the mountain vegetation belt of Slovenia. Forest Snow and Landscape Research 79: 69-80.

Zenner EK, Peck JE (2018). Floating neighborhoods reveal contribution of individual trees to high sub-stand scale heterogeneity. Forest Ecology and Management 412: 29-40. - doi: 10.1016/ j.foreco.2018.01.054

Zenner EK, Peck JE, Hobi ML, Commarmot B (2015). The dynamics of structure across a primeval European beech stand. Forestry 88: 180189. - doi: 10.1093/forestry/cpu042

Zielonka T, Holeksa J, Fleischer P, Kapusta P (2010). A tree-ring reconstruction of wind disturbances in a forest of the Slovakian Tatra Mountains, Western Carpathians. Journal of Vegetation Science 21: 31-42. - doi: 10.1111/j.16541103.2009.01121.x

\section{Supplementary Material}

Fig. S1 - Scatterplot of the range in tree sizes for a given age class and the range in tree ages for a given size class.

Fig. S2 - Tree ages and age differences by diameter size classes.

Fig. S3 - Stem-maps indicating spatial distribution of even-sized neighborhoods.

Link: Zenner_3309@supplo01.pdf 